\title{
Modulatory Role of Eosinophils in Allergic Inflammation: New Evidence for a Rather Outdated Concept
}

\author{
Christianne Bandeira-Melo, Renato SB Cordeiro, Patrícia MR Silva, \\ Marco A Martins ${ }^{+}$
}

\begin{abstract}
Laboratório de Inflamação, Departamento de Fisiologia e Farmacodinâmica, Instituto Oswaldo Cruz, Av. Brasil 4365, 21045-900 Rio de Janeiro, RJ, Brasil
\end{abstract}

The eosinophilic response has been identified as a key alteration in the pathogenesis of asthma and other allergic diseases. A close-correlation between disease severity and eosinophilia, and the eosinophil ability to provide toxic and pro-inflammatory agents are the major elements supporting the interpretation that there is indeed a causal relationship between these phenomena. Nevertheless, controversy still persists since some studies have clearly demonstrated that eosinophil infiltration is not necessarily accompanied by tissue damage or hyperresponsiveness. In addition, there are some examples in the literature in which such alterations are not modified following abrogation of eosinophil influx. In this review it will be argued, based on a model of IgE-dependent pleurisy, that eosinophil infiltration can be associated with down-regulation of allergic inflammatory response. The potential mechanism by which eosinophils could be acting as a immunomodulatory cells in this particular system will also be assessed.

Key words: eosinophil - prostaglandins - allergy - inflammation and pleurisy

Eosinophils are thought to mediate inflammatory and cytotoxic events associated with allergic disorders, including bronchial asthma, rhinitis and urticaria (Gleich et al. 1993, Kroegel et al. 1994). This interpretation is in line with very well established observations in which hypereosinophilic dysfunctions are clearly associated with tissue damage, in particular endomiocardial fibrosis (Wardlaw et al. 1995). It is noteworthy that the eosinophil granule covers a spectrum of preformed highly toxic cationic proteins, including the major basic protein and eosinophil cationic protein, which are able to cause tissue damage by disrupting the membrane structure of target cells (Gleich et al. 1993). Moreover, eosinophils can also generate active substances like PAF, leukotriene $\mathrm{C} 4$, active species of oxygen and several cytokines which can lead to inflammation, bronchoconstriction and mucus hypersecretion, important components of the airway allergic dysfunction (Weller 1994).

The pro-inflammatory effector function of eosinophils has been supported by an extensive amount of studies accumulated throughout the 1980's. One of the important observations is that the treatment of monkeys with anti-ICAM-1 monoclonal anti-

This work was supported by grants from $\mathrm{CNPq}$ and FAPERJ.

${ }^{+}$Corresponding author. Fax: +55-21-590.9490

Received 3 September 1997

Accepted 30 September 1997 body clearly inhibited allergen-induced lung eosinophil influx and also prevented airway hyperresponsiveness (Wegner et al. 1990). Similar findings were obtained following treatment with an anti-IL-5 antibody (TRFK-5) (Mauser et al.1995), reinforcing the interpretation that there is indeed a causal link between eosinophilia and airway hyperreactivity. However, the evidence that another antibody to IL-5 (NC-17) (Nagai et al. 1993), or a soluble IL-5 receptor (Yamaguchi et al. 1994), suppresses allergen-induced BALF eosinophilia with little effect on bronchial hyperreactivity opposes this concept, and points out that the functional role of eosinophils in allergy is still debatle.

It is interesting to note that the current pro-inflammatory profile of eosinophils replaced an opposing concept dominant until the late seventies, in which they were supposed to play an anti-inflammatory role (for an overview see Goetzl et al. 1979). According to early studies, eosinophils may be regarded as immunomodulatory cells because they can release specific enzymes able to neutralise mast cell products including histamine and PAF (Goetzl et al. 1979). The potential down-regulating role of eosinophils is also illustrated by studies showing that a significant amount of a histamine release inhibitor (further characterized as prostaglandins) is generated by human eosinophils following antigenic activation (Hubsher 1975a, b). Additional evidence for the anti-inflammatory effect of these cells comes from the finding that peritoneal neutrophil infiltration is inhibited in animals 
undergoing a local eosinophilia (Cook et al. 1988). The current report is an overview of our recent studies in which an inverse relationship between pleural eosinophilia and antigen-induced exudation has been documented and investigated.

\section{ASSOCIATION OF PLEURAL EOSINOPHILIA WITH DOWN-REGULATION OF ALLERGIC INFLAMMA- TORY RESPONSE}

The pleural cavity is regarded as an interstitial tissue displaying a marked free fluid phase and a minimum fiber matrix represented by the microvilli of the mesothelial cells (Miserocchi et al. 1992). The pleural fluid and its cellular content, including eosinophils, are therefore in close contact with parietal and visceral pleurae, probably influencing and being influenced by them via secreted products. The power of this model is that the exudate can easily be removed by washing the pleural cavity with a physiologic fluid to ensure a complete analysis of inflammatory parameters, including exudate volume, protein content, total and differential leukocyte counts etc. Moreover, the remarkable ease with which the rat pleural space can be sensitised and targeted with allergen and or eosinophil chemoattractants led us to assume that such a model could be indeed useful for understanding the potential interaction between tissue eosinophil enrichment and allergic responsiveness.

Experimental allergic pleurisy can be induced in rats by sensitising the animals with an intrapleural injection of a murine IgE anti-DNP monoclonal antibody, followed by intrapleural antigen challenge $24 \mathrm{~h}$ later (Bandeira-Melo et al. 1995, Lima et al. 1997). The response is characterized by massive mast cell degranulation and intense plasma leakage, assessed by measuring the amount of protein extravasated into the pleural cavity within 4 $\mathrm{hr}$. Allergic pleurisy can also be triggered by intrapleural injection of ovalbumin into rats sensitised with a mixture of adjuvant and ovalbumin 14 days before challenge (Lima et al. 1991). In that case, exudation and mast cell degranulation are accompanied by large numbers of leucocytes in the pleural effluent. There are basically two types of experiments giving information about how an ongoing eosinophilia could affect antigen-induced pleurisy. First, the antigen challenge is performed in sensitised rats undergoing pleural eosinophilia evoked by distinct eosinophil chemoacttractants, and second, the allergic reactivity is assessed in spontaneously eosinophilic rats.

ALLERGEN-INDUCED PLEURISY IN ANIMALS UNDERGOING EOSINOPHILIA CAUSED BY EOSINOPHIL CHEMOACTRACTANTS

It has been reported that LPS failed to induce pleural plasma leakage but caused a biphasic reac- tion of leucocyte accumulation (Bozza et al. 1993). The first phase is marked by a neutrophilic infiltration which peaked from 3 to $6 \mathrm{hr}$ and the second phase by a mononuclear cell infiltration, accompanied by a late long-lasting eosinophilia, which peaked from 24 to $48 \mathrm{hr}$, returning to the baseline level within $120 \mathrm{hr}$ post-challenge. By challenging sensitised rats at different time-points before and after LPS, it is shown that the IgE-mediated pleural exudation is not modified when allergen is administered either at the beginning (neutrophilenriched phase) or at the end of the LPS process. In contrast, exudation is significantly reduced when allergen challenge is performed 48 or $72 \mathrm{hr}$ after LPS, at timings of non-selective or selective eosinophilia respectively. The results are consistent with the interpretation that during LPS-induced pleurisy the refractoriness to allergen is clearly correlated with eosinophil but not neutrophil infiltration.

LPS-induced pleural eosinophilia appears to require a newly generated soluble protein, which is present in the $6 \mathrm{hr}$ LPS pleural washing (LPSPW). The transfer of a cell-free boiled sample of LPS-PW from donors to recipient rats leads to a 3fold increase in the pleural eosinophil population within $24 \mathrm{hr}$, without modifying neutrophil or mononuclear cell counts (Bozza et al. 1993, 1994). The effect of such eosinophilia on allergic protein exudation has also been assessed, and again the presence of eosinophils is associated with a marked refractoriness to the allergen-induced exudation (Bandeira-Melo et al. 1995), giving support to the interpretation that these events are indeed inversely correlated.

Correlation between eosinophil magnitude and down-regulation of allergic pleurisy is also clearly evident following PAF-mediated eosinophilia. Similar to LPS-PW, stimulation by PAF is accompanied by a selective 3 -fold increase in pleural eosinophil counts $24 \mathrm{hr}$ post-challenge. It is noteworthy that consecutive daily intrapleural PAF challenges lead to a progressive and selective augmentation in the number of eosinophils recovered from the pleural cavity $24 \mathrm{hr}$ later (Martins et al. 1993, Silva et al. 1990). In parallel, there is a significant increase in the index of plasma leakage suppression, moving from $68 \%$ to $85 \%$ of blockade following 1 and 4 PAF stimulations respectively. The magnitude of eosinophil infiltration and allergen-evoked exudation in individual bases are shown to be inversely correlated. In contrast, exudation caused by either histamine, 5-HT or the standard mast cell degranulating agent compound 48/ 80 is not modified. The results indicate that the capacity of eosinophils to down-regulate exudation seems to be restricted to the context of the 
allergic reaction. In line with these findings, also actively sensitised rats undergoing eosinophilia evoked by either PAF or ECF-a are shown to be refractory to the allergen challenge, as evidenced by marked down-regulation of both plasma leakage and neutrophil influx (Martins et al. 1993).

ALLERGEN-INDUCED PLEURISY IN ANIMALS UNDERGOING SPONTANEOUS EOSINOPHILIA

AM1/TOR rats have been studied in Brazil because they have a spontaneously systemic eosinophilia (Pimenta et al. 1987). As illustrated in Fig. 1 , blood eosinophil numbers are clearly higher in AM1/TOR rats of different ages than in Wistar rats. Increased eosinophil numbers are also observed in other sites like bone marrow, pleura and peritoneum (Table I). Particularly concerning the pleural space, the eosinophilia is not accompanied by changes in neutrophil, mononuclear or mast cell numbers. In addition, no difference is observed in terms of pleural mast cell stored histamine (Table II). Nevertheless, comparing both sensitised Wistar and AM1-TOR rat, the latter is clearly less sensitive to allergen challenge (Fig. 2). It is noteworthy that this refractoriness has nothing to do with a potential difference in the production of anaphylactic antibodies, since both animals were sensitised with the same amount of IgE anti-DNP monoclonal antibody.

\section{TABLE I}

Increased eosinophil numbers in pleurae, peritoneum and bone marrow of AM1/TOR rats in comparison with Wistar rats

\begin{tabular}{lcc}
\hline Compartment & $\begin{array}{c}\text { Wistar eosinophils } \\
\text { x } 10^{-6} / \text { cavity }\end{array}$ & $\begin{array}{c}\text { AM1/TOR } \\
\text { eosinophils } \\
\text { x 10 }\end{array}$ \\
\hline Pleurae & $1.2 \pm 0.1$ & $2.5 \pm 0.2^{a}$ \\
Peritoneum & $3.0 \pm 0.4$ & $8.8 \pm 0.6^{a}$ \\
Bone marrow & $2.9 \pm 0.6$ & $8.2 \pm 0.8^{a}$ \\
\hline
\end{tabular}

Each value represents the mean \pm S.E.M. from at least 8 animals. $a: P<0.05$ as compared to the appropriated Wistar compartment.

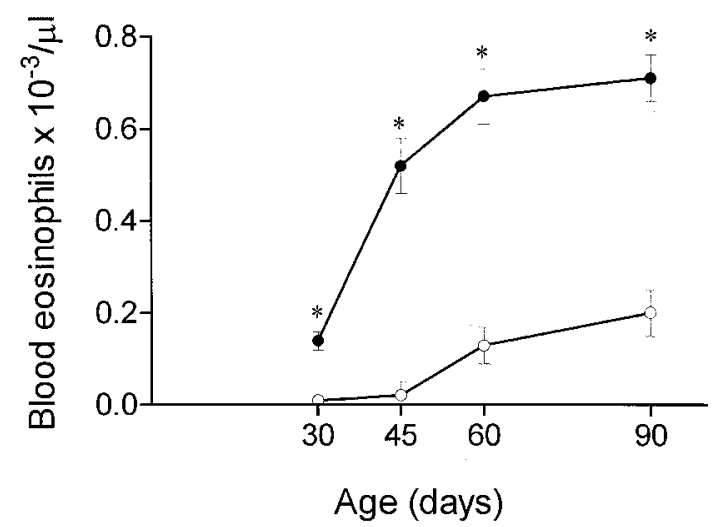

Fig. 1: blood eosinophil numbers of Wistar and AM1/TOR rats of different ages. Each value represents the mean \pm S.E.M. from at least eight animals. ${ }^{*} P<0.05$ as compared to Wistar rats of same age.

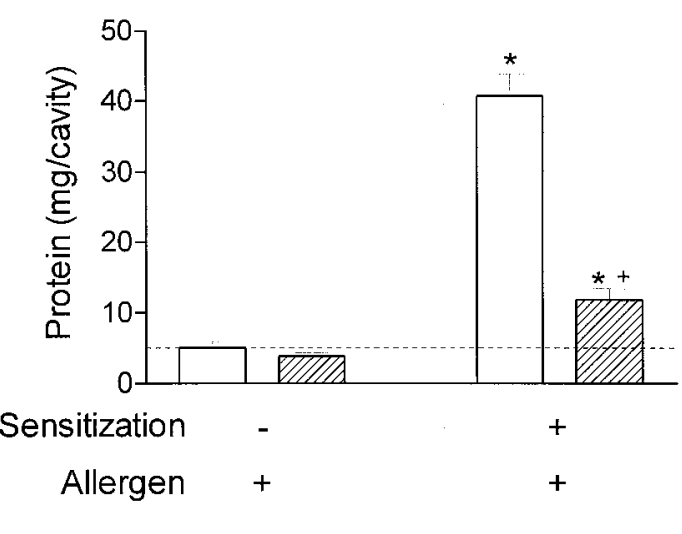

Fig. 2: comparison between pleural sensitivity to allergen challenge of both sensitised Wistar (opened bars) and AM1/TOR rats (right-hatched bars). Each value represents the mean \pm S.E.M. from at least eight animals. All animals received allergen challenge. $* P<0.05$ as compared to the appropriated nonsensitized group. ${ }^{+} P<0.05$ as compared to sensitized Wistar rats.

TABLE II

Comparison between Wistar and AM1/TOR rat pleural spaces

\begin{tabular}{lccccc}
\hline Rat strain & $\begin{array}{c}\text { Protein } \\
\text { (mg/cavity) }\end{array}$ & $\begin{array}{c}\text { Histamine } \\
\text { (ng/cavity) }\end{array}$ & $\begin{array}{c}\text { Mononuclear cells } \\
\text { x } 10^{-6} / \text { cavity }\end{array}$ & $\begin{array}{c}\text { Neutrophils } \\
\text { x } 10^{-6} / \text { cavity }\end{array}$ & $\begin{array}{c}\text { Mast cells } \\
\times 10^{-6} / \text { cavity }\end{array}$ \\
\hline Wistar & $6.7 \pm 0.5$ & $33.9 \pm 4.7$ & $7.8 \pm 0.4$ & $0.0 \pm 0.0$ & $0.6 \pm 0.1$ \\
AM1/TOR & $7.3 \pm 0.6$ & $33.2 \pm 1.7$ & $7.2 \pm 0.1$ & $0.0 \pm 0.0$ & $0.7 \pm 0.1$ \\
\hline
\end{tabular}

Each value represents the mean \pm S.E.M. from at least eight animals. 


\section{SELECTIVE IMPAIRMENT OF PLEURAL EOSINO- PHILIA RESTORES ALLERGIC EXUDATION}

To verify whether there is a causal relationship between eosinophilia and down-regulation of allergen-induced exudation, it is important to evaluate the results of impairing the eosinophil accumulation on the suppressive phenomenon. Basically, two distinct approaches to inhibit eosinophilia have been carried out. Firstly, the eosinophil depletion obtained by means of an intravenous injection of rabbit polyclonal anti-eosinophil antiserum. Secondly, the pharmacological blockade of eosinophilia.

Intravenous injection of the anti-eosinophil antiserum in naive rats leads to a selective reduction in the number of blood and pleural eosinophils 24 hr post-administration. PAF injection $24 \mathrm{hr}$ before allergen challenge induces eosinophil accumulation and reduces allergic exudation. As illustrated in Fig. 3 , the treatment with the anti-eosinophil antiserum inhibits eosinophilia and restores the exudatory response to allergen. Data for the effect of anti-serum treatment in naive and in sensitised animals are shown in Fig. 4 and Table III.
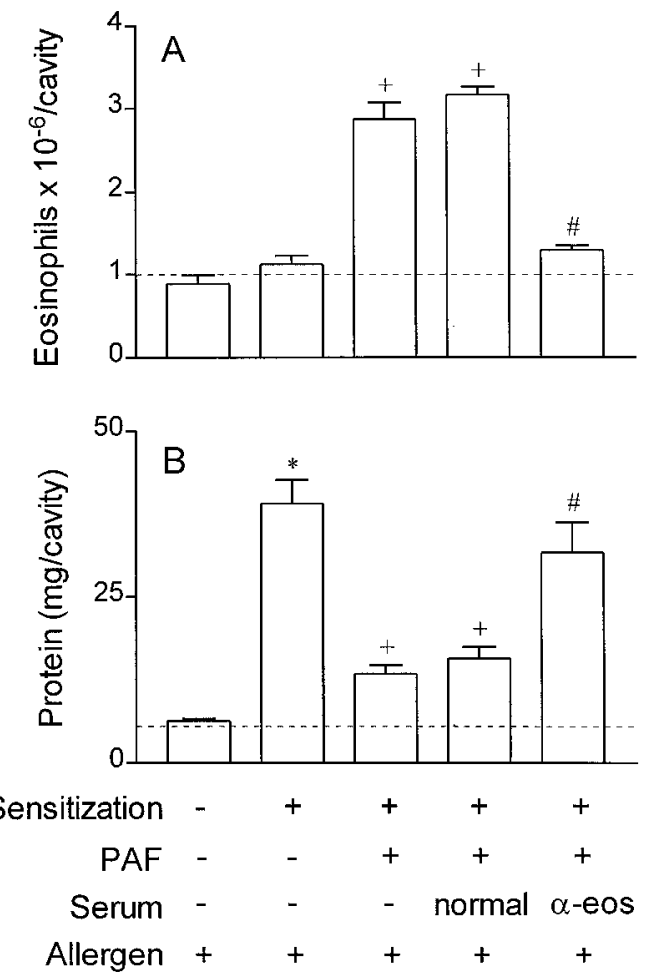

Fig. 3: reversal effect of anti-eosinophil antiserum pre-treatment on inhibition of allergen-induced protein exudation during pleural fluid eosinophilia caused by PAF in sensitized rats. Each value represents the mean \pm S.E.M. from at least eight animals. All animals received allergen challenge. Dotted line represents the background values for eosinophils (A) and total protein (B) in naive rats. ${ }^{*} P<0.05$ as compared to the non-sensitized group. ${ }^{+} P<0.05$ as compared to sensitized PAF-untreated rats. ${ }^{\#} P<$ 0.05 as compared to sensitized PAF-treated rats.
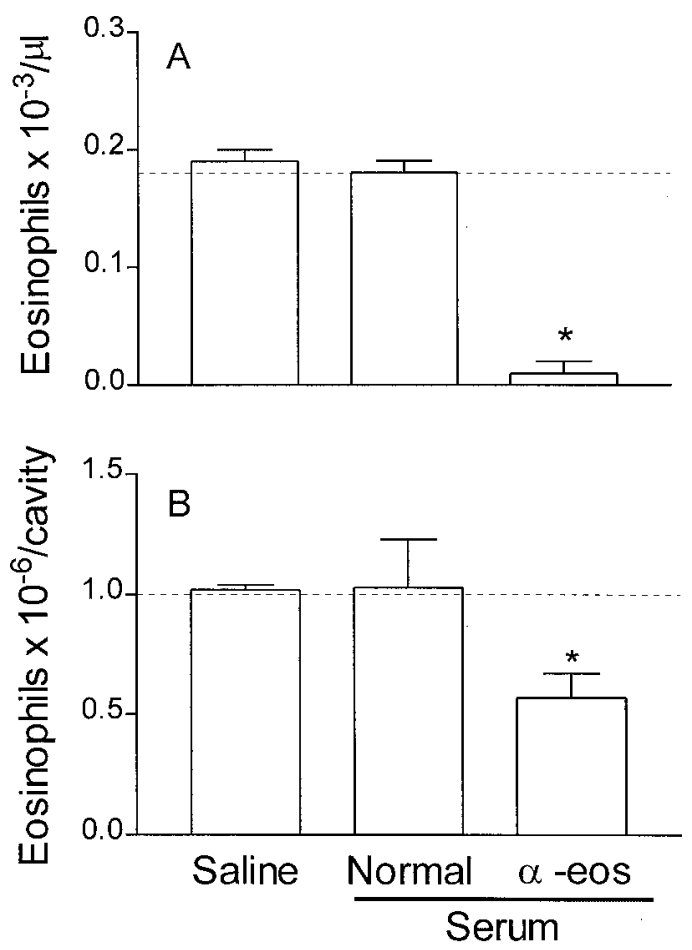

Fig. 4: effect of anti-eosinophil antiserum treatment on blood (A) and pleural fluid (B) eosinophil numbers of naive rats. Each value represents the mean \pm S.E.M. from at least eight animals. ${ }^{*} P<0.05$ as compared to the untreated group.

It has been reported that cetirizine and azelastine are able to inhibit pleural eosinophil accumulation evoked by PAF (Lima et al. 1991, Pasquale et al. 1992). As observed in the immunological depletion of eosinophils, treatments with either cetirizine or azelastine abolish PAF-induced eosinophilia and overcome the refractoriness to the allergen challenge (Martins et al. 1993, BandeiraMelo et al. 1995), reinforcing the interpretation that there is indeed a causative relationship between eosinophilia and the modulation of allergic response.

\section{INVOLVEMENT OF PROSTAGLANDINS IN THE EOSI- NOPHIL-MEDIATED INHIBITION OF ALLERGIC PLEURAL EXUDATION}

Guinea pigs and mice infected with Toxocara canis develop a brief airway hyperreactive response which is, however, followed by a marked tracheal hyporeactivity a few days later (Buijs et al. 1995a, b). Interestingly, the tracheal hyporesponsiveness, which coincides with the presence of large numbers of eosinophils in the airways, is clearly accompanied by an increased concentration of $\mathrm{PGE}_{2}$ in the bronchoalveolar lavage fluid. Moreover, according to the authors, the downward shift in airway responsiveness can be prevented by cyclo- 
TABLE III

Effect of anti-eosinophil antiserum on allergen-induced pleurisy in sensitized rats

\begin{tabular}{lcccc}
\hline Condition & $\begin{array}{c}\text { Protein } \\
\text { (mg/cavity) }\end{array}$ & $\begin{array}{c}\text { Mononuclear } \\
\text { cells x 10 } 6 / \text { cavity }\end{array}$ & $\begin{array}{c}\text { Neutrophils } \\
\text { x 10 } 6 / \text { cavity }\end{array}$ & $\begin{array}{c}\text { Eosinophils } \\
\text { x 10 }\end{array}$ \\
\hline Non-sensitized & $5.5 \pm 0.4$ & $7.9 \pm 0.6$ & $0.0 \pm 0.0$ & $0.9 \pm 0.1$ \\
Sensitized & $45.3 \pm 3.7^{a}$ & $18.3 \pm 1.7^{a}$ & $9.3 \pm 1.4^{a}$ & $0.7 \pm 0.1^{a}$ \\
+ normal serum & $40.7 \pm 1.9$ & $18.9 \pm 1.6$ & $10.7 \pm 2.1$ & $0.9 \pm 0.1$ \\
$+\alpha$-eos serum & $45.2 \pm 2.7$ & $21.4 \pm 1.8$ & $9.5 \pm 0.7$ & $0.4 \pm 0.1^{b}$ \\
\hline
\end{tabular}

Each value represents the mean \pm S.E.M. from at least eight animals. All animals received allergen challenge. $a$ : $P$ $<0.05$ as compared to the non-sensitized group. $b: P<0.05$ as compared to sensitized animals.

oxygenase blockade, but not by inhibitors of lipoxygenase and superoxide formation, suggesting the involvement of prostaglandins in this suppressive phenomenon which occurs in the presence of eosinophilia. It is well established that eosinophils are able to produce $\mathrm{PGE}_{2}$ in distinct systems (Foegh et al. 1986, Giembycz et al. 1990, Kroegel \& Matthys 1993). In fact, in one of the early studies approaching eosinophil function in allergy, Hubsher (1975a, b) demonstrated that immunologically-stimulated human eosinophils could inhibit in vitro histamine release through a prostaglandinmediated mechanism. Interestingly, recent studies have provided evidence that prostaglandins of $\mathrm{E}$ series are indeed able to exert a negative control on the function of pivotal pro-inflammatory cell targets, including mast cells (Hogaboam et al. 1993), lymphocytes (Oppenheimer-Marks et al. 1994, Garrone et al. 1994), neutrophils (Ham et al. 1983) and macrophages (Christman et al. 1993).

In line with these findings, we have verified that pleural spaces which are experiencing a PAFinduced eosinophilia and become hyporesponsive to allergen, also keep an increase in the local $\mathrm{PGE}_{2}$ concentration which, similar to the degree of allergic exudatory suppression, increased with the increasing eosinophil number (Bandeira-Melo et al. 1996). As there is no identifiable enhancement on pleural $\mathrm{PGE}_{2}$ content in naive animals undergoing PAF-related pleural eosinophilia, both ongoing eosinophilia and allergen challenge seem to be essential to evoke the $\mathrm{PGE}_{2}$ production. It is noteworthy that when Wistar and and AM1/TOR rats were compared, now in terms of anaphylactic generation of PGE2, there is indeed a significant increase in PGE2 levels in the pleural fluid of Wistar rats, but the phenomenon was clearly improved in the eosinophilic AM1/TOR rats (Fig. 5).

The effect of prostaglandin biosynthesis inhibitors on allergic inflammation has been extensively investigated. Intravital microscopy of the hamster cheek pouch revealed that either indomethacin or diclofenac pretreatment significantly increased histamine release, plasma leakage and leucocyte ac-

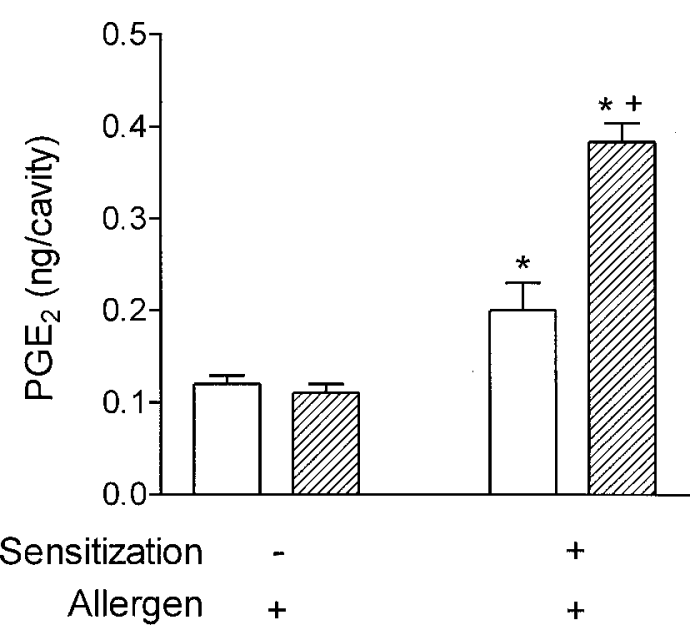

Fig. 5: comparison between $\mathrm{PGE}_{2}$ levels in anaphylactic pleural fluids of Wistar (opened bars) and AM1/TOR (right-hatched bars). Each value represents the mean \pm S.E.M. from at least eight animals. All animals received allergen challenge. $* P<$ 0.05 as compared to the appropriated non-sensitized group. ${ }^{+} P$ $<0.05$ as compared to sensitized Wistar rats

cumulation triggered by antigen. In addition, all these alterations were reversed by $\mathrm{PGE}_{2}$, giving support to the interpretation that endogenous prostaglandins may indeed function as local regulators of the allergic inflammatory response (Raud et al. 1989). The effect of inhibition of cyclooxygenase pathway on the eosinophilia-related attenuation of the allergic protein exudation, with either indomethacin or aspirin, has also been addressed. These drugs fail to modify either pleural plasma leakage or massive mast cell degranulation evoked by antigen challenge in sensitised rats. Nevertheless, they overcome the pleural hyporeactivity to antigen provocation, under conditions where the concomitant eosinophil infiltration driven by PAF remains unaltered (Bandeira-Melo et al. 1996).

If the down-regulatory mechanism described herein is due to local production of $\mathrm{PGE}_{2}$, the exogenous administration of this prostanoid would be expected to have a similar suppressive effect. 
Indeed, orally administered misoprostol, a synthetic analogue of $\mathrm{PGE}_{1}$, attenuates plasma extravasation induced by allergen in actively sensitised animals in intensity comparable to that noted during the localised ongoing eosinophilia. Moreover, misoprostol-mediated suppression of the allergic response is not altered by indomethacin, as expected (Bandeira-Melo et al. 1996). Misoprostol has been shown to specifically bind to PGE receptors (EP receptors) and to exhibit a comparable prostaglandin pharmalogical profile (reviewed in Coleman et al. 1994), including the ability to downregulate immunological events (reviewed in Shield 1995). We have found that $\mathrm{PGE}_{2}$ locally administered failed to alter the allergic exudatory response, which would be a consequence of its worse chemical stability and lesser resistance to the endogenous enzymatic catabolism when compared to misoprostol (reviewed in Shield 1995). It is well accepted that PGEs and their analogues increase intracellular cyclic AMP via a receptor-mediated activation of adenylate cyclase (Coleman et al. 1994). Regulation of cyclic AMP levels is also exerted by cyclic nucleotide phosphodiesterases, among which type IV isoform has been emphasised by its selectivity on cyclic AMP catabolism and sensitivity to rolipram (recently reviewed in Barnes 1995). Indeed, the combined administration of $\mathrm{PGE}_{2}$ plus rolipram significantly inhibited antigeninduced exudation, under conditions where the individual treatments are inactive. This co-operative effect between $\mathrm{PGE}_{2}$ and rolipram has been observed in other experimental models (Sinha et al. 1995) and is in line with the established interpretation that PGEs-induced inhibition of allergic response is indeed mediated by cyclic AMP. Accordingly, the intrapleural injection of the permeable analogue dibutyryl cyclic AMP significantly inhibits the allergen-induced protein exudation (Diaz et al. 1996, Bandeira-Melo et al. 1996), suggesting that an upregulation of the cyclic AMP system may indeed play a pivotal role in the hyporesponsiveness to antigen challenge expressed by the eosinophil enriched sites.

\section{CONCLUDING REMARKS}

We provide herein evidence that allergen-induced pleural exudation is selectively down-regulated in rats which are experiencing an ongoing eosinophilic but not a neutrophilic inflammatory response. The distinct role of eosinophils in the observed suppression was emphasized by chemical and immunological blockade of the eosinophil accumulation, which clearly restored the sensitivity to the allergen. Admitting that eosinophil infiltration and allergen-evoked exudation are inversely correlated, it is remarkable that a small increment in the former is sufficient to down-regulate the latter. This suggests that such an immunoregulatory role of eosinophils could easily take place in the microenviroment of an allergic inflammatory reaction. Furthermore, our results suggest that $\mathrm{PGE}_{2}$ seems to be implicated in the eosinophilia-related attenuation of the allergic pleurisy, in a mechanism which is probably dependent on the activation of cyclic AMP signalling pathway.

Nevertheless, there is no plausible reason for thinking that eosinophils have only one function, so we should not discard the possibility that, under particular conditions, eosinophils might have their immunomodulatory activity impaired. A defect in the eosinophil ability to provide immunomodulatory mediators - like PGE2 - might be a possible explanation for the apparent duality of the eosinophil function.

\section{REFERENCES}

Bandeira-Melo C, Silva PMR, Cordeiro RSB, Martins MA 1995. Pleural fluid eosinophils suppress local IgE-mediated protein exudation in rats. J Leuk Biol 58: 395-402.

Bandeira-Melo C, Singh Y, Silva PMR, Cordeiro RSB, Martins MA 1995. Involvement of prostaglandins in the down-regulation of allergic plasma leakage observed in rats undergoing pleural eosinophilia. $\mathrm{Br}$ J Pharmacol 118: 2192-2198.

Barnes PJ 1995. Cyclic nucleotides and phosphodiesterases and airway function. Eur Respir J 8: 457 462.

Bozza PT, Castro-Faria-Neto HC, Martins MA, Laranjeiras AP, Perales JE, Silva PMR, Cordeiro RSB 1993. Pharmacological modulation of lipopolysaccharide-induced pleural eosinophilia in the rat: a role for a newly generated protein. Eur $J$ Pharmacol 248: 41-47.

Bozza PT, Castro-Faria-Neto HC, Penido C, Laranjeiras AP, Silva PMR, Martins MA, Cordeiro RSB 1994. IL-5 accounts for the mouse pleural eosinophil accumulation triggered by allergen but not by LPS. Immunopharmacology 27: 131-135.

Buijs J, Egbers MWEC, Lokhorst WH, Savelkoul HFJ, Nijkamp FP 1995a. Toxocara-induced eosinophilic inflammation. Airway function and effect of antiIL-5. Am J Respir Crit Care Med 151: 873-875.

Buijs J, Egbers MWEC, Nijkamp FP 1995b. Toxocara canis-induced airway eosinophilia and tracheal hypereactivity in guinea pigs and mice. Eur $J$ Pharmacol 293: 207-215.

Christman BW, Christman JW, Dworski R, Blair IA, Prakash C 1993. Prostaglandin $E_{2}$ limits arachidonic acid availability and inhibits leukotriene $\mathrm{B}_{4}$ synthesis in rat alveolar macrophages by a non phospholipase $\mathrm{A}_{2}$ mechanism. J Immunol 151: 2096-2104.

Coleman RA, Smith WL., Narumiya S 1994. VIII. International Union of Pharmacology Classification of Prostanoid Receptors: properties, distribution, and structure of the receptors and their subtypes. Pharmacol Rev 46: 205 - 229. 
Cook RM, Musgrove NRJ, Smith H 1988. Relationship between neutrophil infiltration and tissue eosinophilia in the rat. Int Arch Appl Immunol 87: 105108.

Diaz BL, Serra MF, Alves AC, Cordeiro RSB, Martins MA, Silva PMR 1996. Local exposure to salbutamol or $\mathrm{Bt}_{2}$ cyclic AMP inhibts pleural exudation and leukocyte influx caused by atigen in rats. Eur $J$ Pharmacol 296: 173-180.

Foegh ML, Maddox YT, Ramwell PW 1986. Human peritoneal eosinophils and formation of arachidonate cyclooxygenase products. Scand J Immunol 23: 599603.

Garrone P, Galibert L, Rousset F, Fu SM, Banchereau J 1994. Regulatory effects of prostaglandins $E_{2}$ on the growth and differentiation of human B lymphocytes activated through their CD40 antigen. $J$ Immunol 152: 4282-4290.

Giembycz MA, Kroegel C., Barnes PJ 1990. Platelet activating factor stimulates cyclooxygenase activity in guinea pig eosinophils: concerted biosynthesis of thromboxane $\mathrm{A}_{2}$ and E-series prostaglandins. J Immunol 144: 3489-3497.

Gleich GJ, Adolphson CR, Leiferman KM 1993. The biology of eosinophilic leukocyte. Annu Rev Med 44: 85-101.

Goetzl EJ, Weller PF \& Valone FH 1979. Biochemical and functional bases of the regulatory and protective roles of the human eosinophil, p. 157-167. In G Weissmann Advances in Inflammation Research. Raven Press, New York.

Ham EA, Soderman DD, Zaneth ME., Dougherty HW, McCauley E, Kuehl FA 1983. Inhibition by prostaglandins of leukotriene $\mathrm{B}_{4}$ release from activated neutrophils. Proc Natl Acad Sci USA 80: 4349-4353.

Hogaboam CM, Bissonnette EY, Chin BC, Befus AD, Wallace JL 1993. Prostaglandins inhibt inflammatory mediator release from rat mast cells. Gastroenterology 104: 122-129.

Hubsher T 1975a. Role of the eosinophil in the allergic reactions. I. EDI - an eosinophil-derived inhibitor of histamine release. J Immunol 114: 1379-1388.

Hubsher T 1975b. Role of the eosinophil in the allergic reactions. II. Release of prostaglandins from human eosinophilic leukocytes. J Immunol 114: 1389-1393.

Kroegel C \& Matthys H 1993. Platelet-activating factor-induced human activation. Generation and release of cyclo-oxygenase metabolites in human blood eosinophils from asthmatics. Immunology 78: 279-285.

Kroegel C, Warner JC, Virchow JR, Matthys H 1994. Pulmonary immune cells in health and disease: the eosinophil leukocyte (Part II). Eur Respir J 7: 743760.

Lima MCR, Martins MA, Perez SAC, Silva PMR, Cordeiro RSB, Vargaftig BB 1991. Effect of azelastine on platelet-activating factor and antigeninduced pleurisy in rats. Eur J Pharmacol 197: 201207.

Lima MCR, Prouvost-Danon A, Silva PMR, Chagas MSS, Calheiros AS, Cordeiro RSB, Latine D, Bazin H, Ryan US, Martins MA 1997. Studies on the mechanism involved in antigen-evoked pleural in- flammation in rats: contribution of $\mathrm{IgE}$ and complement. J Leukoc Biol 61: 286-292.

Martins MA, Castro-Faria-Neto HC, Bozza PT, Silva PMR, Lima MCR, Cordeiro RSB, Vargaftig BB 1993. Role of PAF in the allergic pleurisy caused by ovalbumin in actively sensitized rats. J Leuk Biol 53: 104-111.

Mauser PJ, Pitman AM, Fernandez X, Foran, SK, Adams GK, Kreutner W, Egan RW, Chapman RW 1995. Effects of an antibody to IL-5 in a monkey model of asthma. Am J Respir Crit Care Med 152: 467-472.

Miserocchi G, Venturoli D, Negrini D, Gilardi MC, Bellina R 1992. Intrapleural fluid movements described by a porous flow model. J Appl Physiol 73: 2511-2516.

Nagai H, Yamaguchi S, Inagaki N, Tsuruoka N, Hitoshi Y, Takatsu K 1993. Effect of anti-IL-5 monoclonal antibody on allergic bronchial eosinophilia and airway hyperresponsiveness in mice. Life Sci 53: 243247.

Oppenheimer-Marks N, Kavanaugh AF, Lipsky PE 1994. Inhibition of the transendothelial migration of humanT lymphocytes by prostaglandin $\mathrm{E}_{2} . J$ Immunol 152: 5703-5713.

Pasquale CM, Silva PMR, Lima MCR, Diaz BL, Rihoux JP, Vargaftig BB, Cordeiro RSB, Martins MA 1992. Suppression by cetirizine of pleurisy triggered by antigen in actively sensitized rats. Eur J Pharmacol 223: 9-14.

Pimenta PFP, Santos MAV, Souza W 1987. Fine structure and cytochemistry of the interaction between Leishmania mexicana and rat neutrophils and eosinophils. J Submicrosc Cytol 19: 387-395.

Raud J, Dahlen SE, Sydbom A, Lindbom L, Hedqvist P 1989. Prostaglandins modulation of mast cell-dependent inflammation. Agents Actions 26: 42-44.

Shield MJ 1995. Novel applications of misoprostol. PharmacTher 65: 125-147.

Silva PMR, Martins MA, Castro-Faria-Neto HC, Bozza PT, Cruz HN, Dias MTRP, Cordeiro RSB, Vargaftig BB 1990. Pleural eosinophil infiltration induced by PAF-acether is not a desensitizable phenomenon. Braz J Med Biol Res 23: 1009-1013.

Sinha B, Semmler J, Eisenhut T, Eigler A, Endres S 1995. Enhanced tumor necrosis factor suppression and cyclic adenosine monophosphate accumulation by combination of phosphodiesterase inhibitors and prostanoids. Eur J Immunol 25: 147-153.

Wardlaw AJ, Moqbel R, Kay B 1995. Eosinophil: biology and role in disease, p. 151-266. In Advances in Immunology Academic Press. Inc., London.

Wegner CD, Gundel RH, Reilly P, Haynes N, Letts LG, Rothlein R 1990. Intercellular adhesion molecule-1 (ICAM-1) in the pathogenesis of asthma. Science 247: 456-459.

Weller PF 1994. Eosinophils: structure and functions. Curr Opinion Immunol 6: 85-90.

Yamaguchi S, Nagai H, Tanaka H, Tsujimoto M., Tsuruoka N 1994. Time course study for antigeninduced airway hyperreactivity and the effect of soluble IL-5 receptor. Life Sci 54: 471-475. 